\title{
Comparing a Computer Agent with a Humanoid Robot
}

\author{
Aaron Powers, Sara Kiesler, Susan Fussell, Cristen Torrey \\ Human Computer Interaction Institute \\ Carnegie Mellon University \\ 5000 Forbes Avenue \\ Pittsburgh, PA 15213 \\ \{apowers, kiesler, sfussell, ctorrey\}@cs.cmu.edu
}

\begin{abstract}
HRI researchers interested in social robots have made large investments in humanoid robots. There is still sparse evidence that peoples' responses to robots differ from their responses to computer agents, suggesting that agent studies might serve to test HRI hypotheses. To help us understand the difference between people's social interactions with an agent and a robot, we experimentally compared people's responses in a health interview with (a) a computer agent projected either on a computer monitor or life-size on a screen, (b) a remote robot projected life-size on a screen, or (c) a collocated robot in the same room. We found a few behavioral and large attitude differences across these conditions. Participants forgot more and disclosed least with the collocated robot, next with the projected remote robot, and then with the agent. They spent more time with the collocated robot and their attitudes were most positive toward that robot. We discuss tradeoffs for HRI research of using collocated robots, remote robots, and computer agents as proxies of robots.
\end{abstract}

\section{Categories and Subject Descriptors}

H.1.2 [Models and Principles]: User/Machine Systems - Human factors, Software psychology. H.5.2 [Information Interfaces and Presentation]: User Interfaces - Evaluation/methodology, Theory and methods.

\section{General Terms}

Design, Experimentation, Human Factors, Theory.

\section{Keywords}

Human-robot interaction, embodiment, social robots.

\section{INTRODUCTION}

In the hallways of a recent robotics workshop, researchers in human-robot interaction were overheard discussing the challenges of obtaining and maintaining social robots for studies of human robot interaction. When someone proposed that, for most purposes, embodied agents presented on a computer monitor would work as well, there was vociferous argument about the

Permission to make digital or hard copies of all or part of this work for personal or classroom use is granted without fee provided that copies are not made or distributed for profit or commercial advantage and that copies bear this notice and the full citation on the first page. To copy otherwise, or republish, to post on servers or to redistribute to lists, requires prior specific permission and/or a fee.

HRI'07, March 8-11, 2007, Arlington, Virginia, USA.

Copyright 2007 ACM 978-1-59593-617-2/07/0003...\$5.00 validity of studying agents as proxies for social robots. Would the social impact of an agent be the same as that of a robot? Would an agent have an equal ability to guide users through social interaction, or to engage their attention? People's interactions with computer agents on a screen - a computer-generated character or talking head - may be qualitatively and quantitatively unlike the responses they give to robots. Agents may appear more fantastic, more remote, or less humanlike than robots. Agents may be less engaging and likeable than robots. Conversational grounding may suffer, as well as learning.

There is little scientific literature comparing embodied computer agents with robots. Yamato et al. [23] compared a computer agent rabbit with a small rabbit robot. Each recommended a color name to participants. These authors found that the agent had more impact on participants' choices of names although participants felt closer to the robot. Embodiment itself is not always associated with more or better social impact. For example, Berry et al. [1] compared an animated embodied agent, GRETA, with the same agent using voice or text only. Participants rated GRETA more likable and helpful but GRETA caused the worst memory performance, possibly because the embodied agent was distracting.

We believe that what is needed in this literature are systematic studies comparing agents and robots on dimensions that may be important in social interaction with robots. To help answer the question empirically of how an agent and a robot cause similar and different social responses in people, we conducted an experiment in which we compared the effects of an agent and a robot on several key aspects of social behavior and attitudes.

In the next sections, we briefly discuss literature on some social dimensions of agents versus robots. This literature motivated the experimental comparisons we made.

\subsection{Realism and Lifelikeness}

Computer agents can be created to have a surface resemblance to people or other living beings. They can move in lifelike ways that robots cannot-swim, fly, or run. In this sense they can be far more realistic and lifelike than robots today. Studies of animism show that certain kinds of movement automatically cause even babies to perceive an object as alive [15]. On the other hand, robots exist in physical space, and they can move around our own environment. Even if they cannot travel, robots' various parts (such as head, lips, arms) can move in three-dimensional space or manipulate objects or even touch the user. In accomplishing such actions, the robot must obey physical principles. In this sense, robots are realistic in a way that a computer agent is not. No studies we know of have compared the experienced realism or lifelikeness of comparable agents and robots-for instance, a 
computer agent that looks and acts like a robot with a similar real robot.

\subsection{Physical Proximity}

A robot may have more social impact than an agent simply because it is present in the environment with people whereas an agent is perceived as in the computer. To our knowledge, no studies have examined this dimension of robots, for example, by comparing a remote robot projected on a screen with the same robot in the location of the participant. However, an extensive literature exists on the social impact of physical proximity between people [9]. By extension, this literature suggests that a robot will have more social impact than an agent merely because of its physical proximity.

The physical proximity of others works through several processes. First, the presence of others is physiologically arousing, causing a so-called "social facilitation" effect in which the physical presence of an observer or partner causes faster responses but sometimes distraction and reduced accuracy[25]. The physical presence of others also increases people's concern with being evaluated, or "evaluation apprehension" [3]. Evaluation apprehension may be responsible for people's increased concern and conformity with others in their presence, with choking effects, e.g.,[4], and with reduced disclosure of sensitive information in the presence of others [3]. The literature suggests that people reveal more in a computer interview than in a face-to-face interview [16]. If these results apply to the agent-robot comparison, then we can expect that a robot will have more influence than an agent, but that the robot will not elicit as much disclosure as the agent.

To discern whether a robot's social impact derives from its physical proximity, we can compare a remote robot communicating through telepresence or projected presence with a collocated robot. Bradner and Mark [2] reported that people were affected by remote two-way video observation (as compared with none), but in many other studies remote communication reduced social facilitation effects and evaluation apprehension, and increased disclosure of sensitive information. Many studies also show that people are more likely to bond with those they meet face to face and will work out differences with them. Collocated teams as compared with distributed teams or remote partners have more trouble commanding the attention of teammates and developing trust, coordinating work, resolving conflict, and engendering high motivation, e.g., [5]. By extension, a remote robot could have less social impact than a collocated robot.

\subsection{Sense of Presence}

It has been argued that physical presence may be less important than the sense of presence - the subjective experience of being physically located in the environment created by the computer or transmitted by the teleoperator system, rather than in the place in which the device is actually located e.g., [18]. If so, a remote robot projected life-size on a screen in front of a user might have the same social impact as a robot in the room if it conveys a sense of presence. Many investigators and designers of virtual environments, simulators, and teleoperator systems consider a strong sense of presence to be a desirable attribute and thus a selfevident goal of their devices. Some believe more presence improves users' performance of the task for which the device is being used. Participants frequently claim that they did better on a task because of the strong sense of presence they experienced, e.g., [24]. However, a causal link has not been determined [21]. If a link exists, and a remote robot engenders people's sense of presence, a single operator could maintain a robot for use by many others at remote distributed locations.

\subsection{Size}

A robot may have more social impact than an agent simply because it is larger than the computer agent. Consider, for instance, the robots Robovie and Asimo, two robots each about the size of a toddler. As small as these robots are, they are considerably larger than a computer agent the average user sees on a computer screen. Yamato et al.[23] created a tiny robot for their experiment comparing an agent and a robot, but even so it was much larger than their computer agent. There is some literature on human size and social impact. For instance, tall people earn more money than short people [8]. When a video conferencing system makes a person look artificially taller, that person has more social impact than when the camera makes him or her look artificially shorter [6]. Also, Tan and Czerwinski [19] showed that displays on a large screen command attention and have more social impact than displays on a small screen. Visitors were more likely to glance over a user's shoulder to read information on a large display than on a smaller display.

Each of the dimensions discussed above-realism, proximity, presence, and size - represents a social factor that may distinguish a computer agent that looks like a robot from an actual robot. Our study addressed these dimensions.

\section{STUDY DESIGN AND METHOD}

In the experiment, we compared a robot with an embodied computer agent that looked like the robot. The design was a between-groups design; each participant was randomly assigned to only one of four conditions. The four conditions were computer agent on a computer monitor, computer agent projected life-size on a screen, remote robot projected life-size on a screen, and collocated robot. The agent was modeled on the robot, the Nursebot robot, Pearl (see Figures 1, 2). In the robot conditions, the Nursebot robot was either in a different room but projected live onto a large screen in front of the participant (Figure 3) or collocated with the participant (Figure 4). Care was taken to make sure the robot was near to the same size in both the projected and collocated conditions.

We predicted the agent (whether on a monitor or screen) would seem less lifelike and would cause less sense of presence than the robot, and that the remote robot would seem less real and would cause less sense of presence than collocated robot. If so, social impact should be ordered as follows: collocated robot $>$ remote robot $>$ agents. From the literature, we hypothesized:

H1. The robots as compared with the agents will be more engaging and better liked, will command more attention and social influence, but will garner less disclosure of personal information.

H2. The collocated robot will be more engaging and better liked, will command more attention and social influence, but will garner less disclosure of personal information than the remote robot, projected life-size on a large screen.

H3. The projected agent (life-size on a large screen) will be more engaging and be better liked, will command more attention and social influence, but will garner less disclosure of personal information than the agent viewed on a computer monitor. 


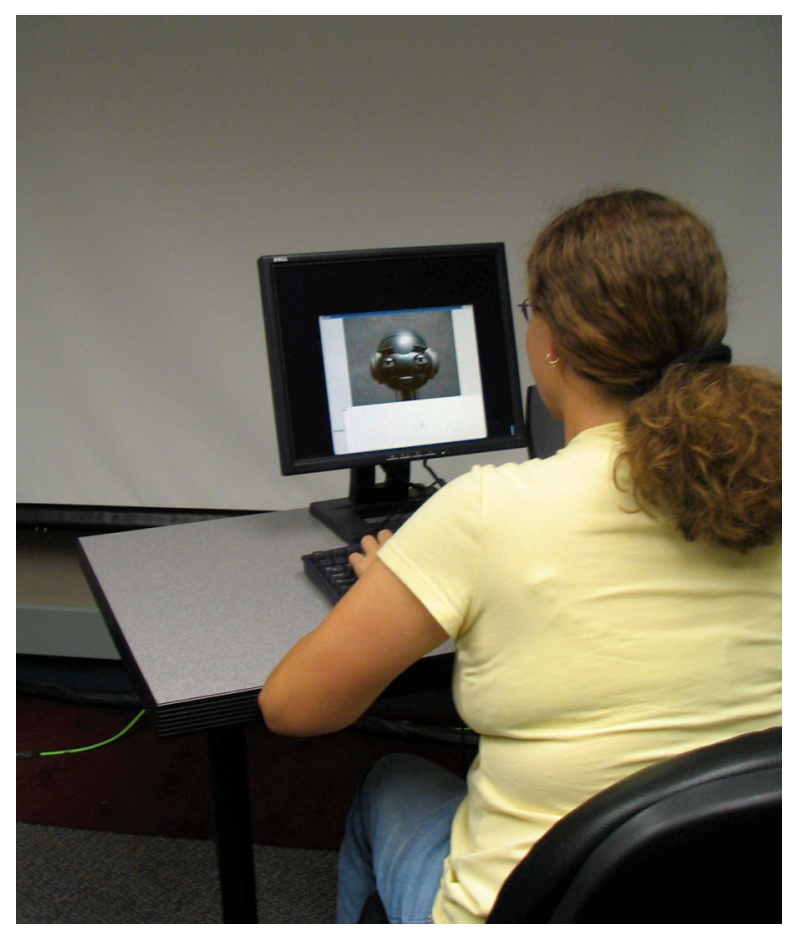

Figure 1. Agent on computer monitor.

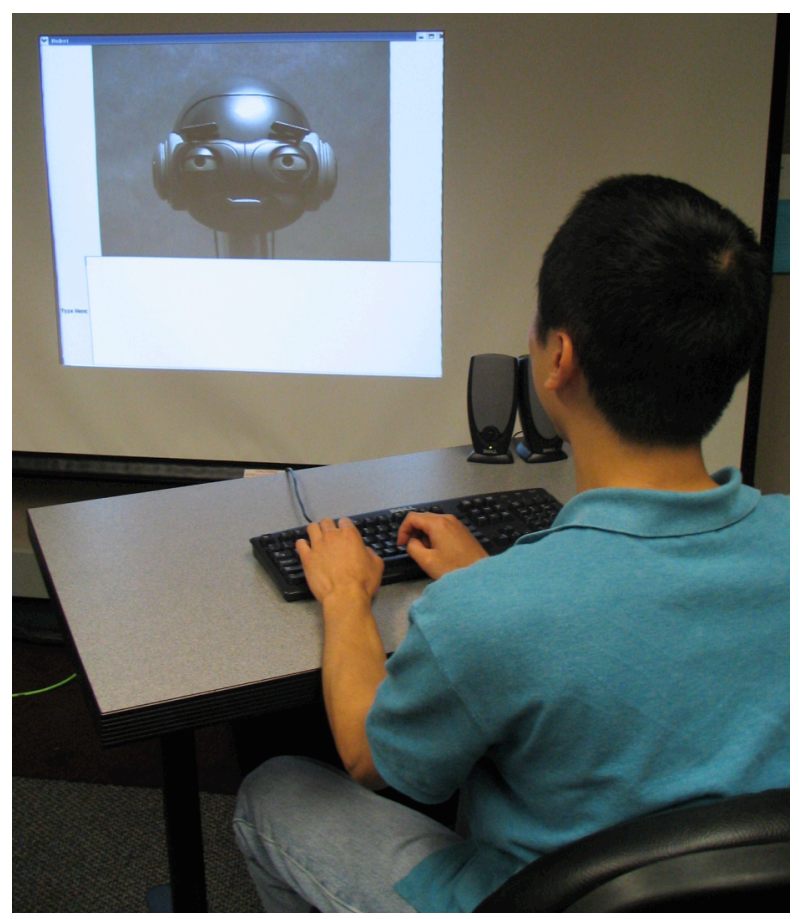

Figure 2. Agent projected on large screen.

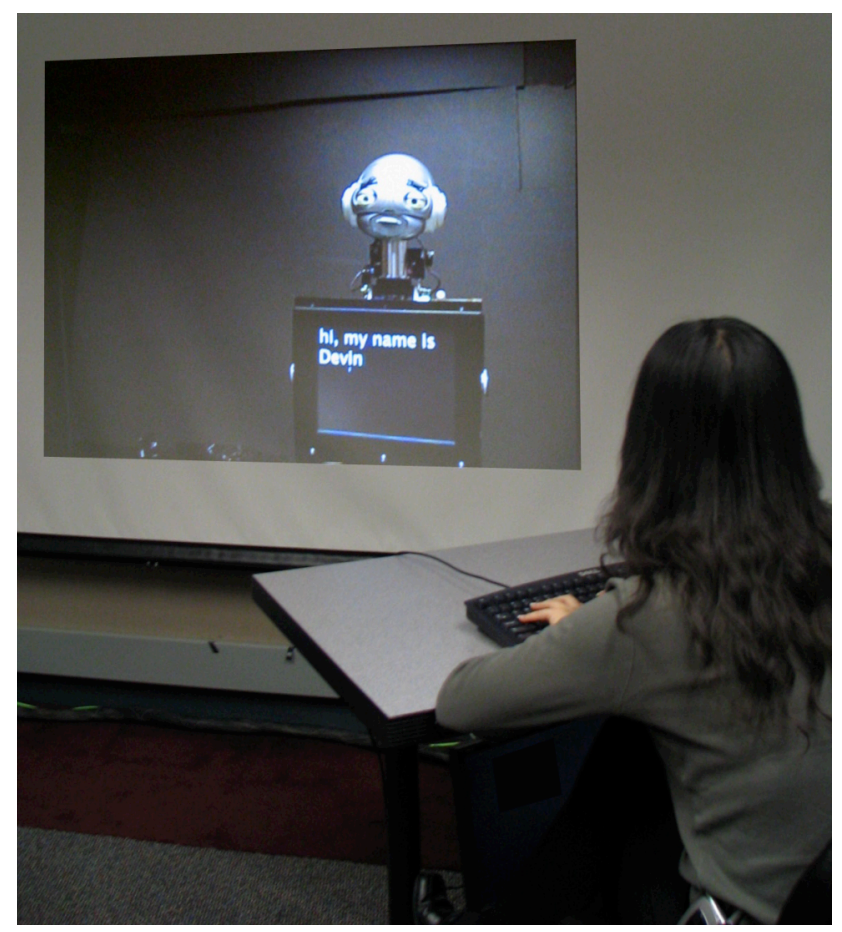

Figure 3. Remote robot projected on large screen.

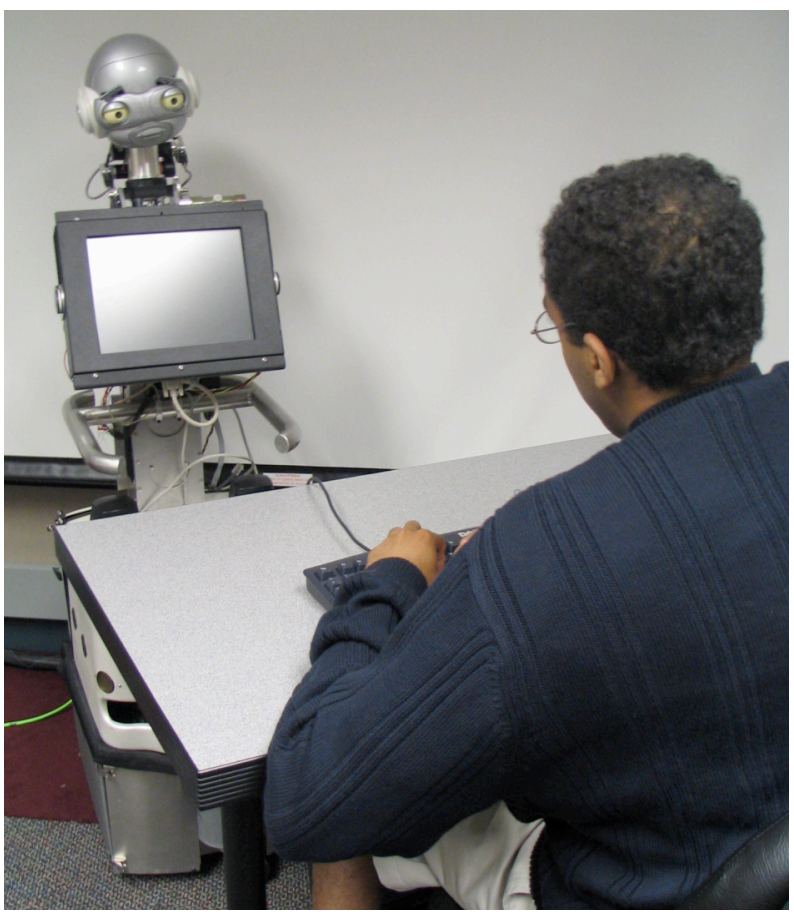

Figure 4. Collocated robot in room. 


\subsection{Participants}

One hundred and thirteen participants were recruited from the community in and around Carnegie Mellon University. They were paid US\$10 in cash when they came into the lab. Participants were $52 \%$ male, with an average age of 26 years (range 17-57).

The 113 participants represented 56 diverse fields of study, including architecture, film and theatre, business, medicine, and journalism. Only 10 participants were in CS, robotics, or ECE.

We ran more participants in each robot condition (remote robot $\mathrm{n}$ $=38$, collocated robot $\mathrm{n}=37$ ) than in each agent condition $(\mathrm{n}=$ 19). In half of each robot condition, the robot was supposed to navigate to the participant at the beginning of the experiment. This manipulation did not work in some instances, and the manipulation did not have systematic effects on the conversation results that are reported here.

\subsection{Procedure}

When the participants arrived at the experimental lab, the experimenter told them that their goal was to "have a discussion with this robot about basic health habits," and that the robot would ask questions about their health and habits.

Participants were able to converse with the robot by typing on a keyboard. The robot asked the participants about general health habits, such as exercise, eating, weight and height, and flossing. The robot also asked some sensitive disclosure questions, such as "Have you ever deliberately said something against someone, or said something to hurt their feelings?" The dialogue took 10-15 minutes.

\subsection{Equipment}

The robot head was measured to assure that the robot's size remained relatively the same between conditions.

The robot stood 53" tall in both the robot collocated and the remote robot projected conditions (though in the remote robot projected condition the bottom of the robot was cut off). The robot's head was 8" wide and 7" high. In the remote robot projected condition, the sizes were measured to make sure that the robot was, on average, the same size on the projection. If the robot was moving, the size varied on the projector, but was kept close to the robot's actual size. The collocated robot was 44" away from the subject (Figure 4). The large screen that the remote robot was projected on to was 50" away (Figure 3).

The agent's picture was $400 \times 350$ pixels. The agent's head on the LCD screen was 4.5 " wide and 3.5 " tall, and 21 " away from the subject (Figure 1). The agent's head on the projected screen was 16 " tall and 13" wide, and was 50" away (Figure 2).

As noted above, the robot Nursebot was used for this experiment. The Nursebot has an animated face with 17 degrees of freedom, including eyebrows, eyelids, eyes, mouth, and neck. A programmer scripted the robot face's motions to match the content of the dialogue. In the collocated and remote projected robot conditions, the lips were synched with the male voice, using Theta [10] [19]. As expected, participants rated the agent/robot as more masculine than feminine $(\mathrm{F}[1,109]=4.9, \mathrm{p}<.05)$.

The robot spoke all of its lines aloud, and did not display its words on the screen. Its dialogue was built using a custom-built dialogue engine [12]. Because speech synthesis is sometimes difficult to understand, in recruiting for the study we asked for only native English speakers. The participants typed all of their responses.
Their typing appeared on a monitor on the robot or the projected image, below the head. We did not use speech recognition because we wanted to allow users to say very descriptive, full sentences, and we wanted to have a record of what they said accurately for textual analysis.

After the conversation ended, the participant completed a 120 question online survey that took 10-15 minutes to complete. While the participant was filling out the survey, the experimenter pointed to a bowl with a mix of different snack bars and told them they could eat as many as they liked while completing the survey. The bowl was a prearranged set of candy bars and health bars, and was counted and replenished after each participant.

\subsection{Dependent Variables}

We measured social impact as revealed in participants' behavior and attitudes, drawing from the social psychological literature for conceptual and operational measures. The main behavioral measures are described in Table 1. There are four categories of behavior measured directly from participants' actions: engagement (time spent talking with the robot); disclosure (whether the participants admitted socially undesirable behavior to the robot, and how much they revealed about their socially undesirable behaviors); social influence (whether the participants told the robot they would implement healthier behavior [11]; whether they ate fewer calories), and conversational memory (how much participants recognized or recalled what the robot told them). The agent's/robot's requests for sensitive and personal information were taken from the Crowne-Marlowe social desirability scales [17].

Table 1. Dependent Behavioral Variables

\begin{tabular}{|l|l|l|}
\hline $\begin{array}{l}\text { Social } \\
\text { Response } \\
\text { Categories }\end{array}$ & \multicolumn{1}{|c|}{ Variable } & \multicolumn{1}{|c|}{ Measure } \\
\hline Engagement & $\begin{array}{l}\text { Time with } \\
\text { robot }\end{array}$ & $\begin{array}{l}\text { How long did the participant } \\
\text { spend talking with the robot? }\end{array}$ \\
\hline Disclosure & $\begin{array}{l}\text { Disclosure of } \\
\text { sensitive } \\
\text { information }\end{array}$ & $\begin{array}{l}\text { Did the participant admit } \\
\text { negative behavior? }\end{array}$ \\
\cline { 2 - 3 } & $\begin{array}{l}\text { How much did the participant } \\
\text { say reveal about } \\
\text { himself/herself? (Word } \\
\text { count) }\end{array}$ \\
\hline $\begin{array}{l}\text { Social } \\
\text { influence }\end{array}$ & Intentions & $\begin{array}{l}\text { Did the participant agree to } \\
\text { read for pleasure, eat salads, } \\
\text { exercise (how often), and } \\
\text { floss his/her teeth next week? }\end{array}$ \\
\cline { 2 - 3 } & Eating & $\begin{array}{l}\text { Did the participant eat less } \\
\text { caloric candy bars? }\end{array}$ \\
\hline $\begin{array}{l}\text { Conversational } \\
\text { memory }\end{array}$ & $\begin{array}{l}\text { Memory of } \\
\text { information } \\
\text { from robot }\end{array}$ & $\begin{array}{l}\text { Did the participant remember } \\
\text { what the robot said about } \\
\text { healthy behavior? (Forced } \\
\text { choice and open recall) }\end{array}$ \\
\hline
\end{tabular}

We used a posttest questionnaire to obtain self-reports of participants' subjective experiences of their conversations with the agent/robot and their attitudes about it. We primarily used scales and items from our own and others' research [4][21]. The 
subjective experience items included questions about participants' mental workload, enjoyment and mood, and sense of presence. The attitude items included questions about the lifelikeness and humanlikeness of the agent/robot, and its traits. We used factor analysis to confirm that scales reflected coherent factors, and conducted tests of item reliability, reported as Cronbach's alphas in Table 2.

Table 2. Subjective Self-Report Variables

\begin{tabular}{|c|c|c|}
\hline $\begin{array}{l}\text { Social } \\
\text { Response } \\
\text { Categories }\end{array}$ & Variable & Measure \\
\hline \multirow[t]{4}{*}{$\begin{array}{l}\text { Mental/ } \\
\text { emotional state }\end{array}$} & Mental state & $\begin{array}{l}\text { NASA workload } \\
(3 \text { items, } \alpha=.65 \text { ). }\end{array}$ \\
\hline & Mood & $\begin{array}{l}\text { Affect } \\
(4 \text { items, } \alpha=.83)\end{array}$ \\
\hline & Enjoyment & $\begin{array}{l}\text { Conversation helpfulness } \\
\text { (9 items, } \alpha=.91) \\
\text { Good content } \\
\text { ( } 3 \text { items, } \alpha=.69) \\
\text { Enjoyment } \\
(7 \text { items, } \alpha=.87)\end{array}$ \\
\hline & $\begin{array}{l}\text { Sense of } \\
\text { presence }\end{array}$ & $\begin{array}{l}\text { Felt presence, real discussion, } \\
\text { same place } \\
(3 \text { items, } \alpha=.74)\end{array}$ \\
\hline \multirow[t]{2}{*}{$\begin{array}{l}\text { Attitudes } \\
\text { toward } \\
\text { agent/robot }\end{array}$} & Traits & $\begin{array}{l}\text { Dominant } \\
(4 \text { items, } \alpha=.83) . \\
\text { Trustworthy } \\
(5 \text { items, } \alpha=.83) . \\
\text { Sociable } \\
(10 \text { items, } \alpha=.89) . . \\
\text { Responsive } \\
(6 \text { items, } \alpha=.88) . \\
\text { Competent } \\
(14 \text { items, } \alpha=.93) \text {. } \\
\text { Respectful } \\
(3 \text { items, } \alpha=.76) \text {, }\end{array}$ \\
\hline & Lifelikeness & $\begin{array}{l}\text { Humanlike, lifelike, } \\
\text { machinelike (rev.), natural } \\
\text { (4 items, } \alpha=.83 \text { ). }\end{array}$ \\
\hline
\end{tabular}

Note._Cronbach's alpha $=\alpha$

\section{RESULTS}

\subsection{Analysis Strategy}

We used analysis of variance and planned contrasts to compare the agent with the robots across the 113 participants. First, we compared responses in the four main experimental conditions (monitor and projected agents, projected remote robot, collocated robot). The planned contrasts compared the agent conditions with the robot conditions, and the collocated robot condition with the remote robot. We also examined differences within the agent conditions of interacting with the agent on a monitor versus projected on a screen.

\subsection{Effects of Agents vs. Remote Robot vs. Collocated Robot on Social Behavior}

We ran preliminary analyses to be sure that the agent and robot could be understood equally. A few participants, especially in the collocated robot condition, were not fluent English speakers and had trouble understanding the machine speech of the robot. The questionnaire item for speech comprehension, "I was able to understand what the robot was saying," predicted participants' not completing answers or saying "I don't understand." Therefore, in the analyses of variance we used scores on the speech comprehension item as a covariate. In some analyses reported below, there are fewer than 113 scores due to machine malfunction and missing logging data or participants' not responding to a questionnaire item.

Because men and women may differ in their conversational demeanor (and because the robot had a male voice) we used gender of the participant as a control variable in the behavioral analyses.

\subsubsection{Engagement}

We predicted the collocated robot would be most engaging. We tested the amount of time that the participant spent with the robot from the robot's first greeting to the robot's last word. The agent, remote robot, and collocated robot conditions differed marginally significantly overall $(\mathrm{F}[3,105]=2.2, \mathrm{p}=.08)$. Relevant to $\mathrm{H} 1$, participants spent significantly more time with either robot (remote projected robot 13.8 minutes; collocated robot 13.7minutes) than with either agent (monitor agent 12.6 minutes; projected agent, 13.0 minutes; contrast $\mathrm{F}=5.5, \mathrm{p}<.05$ ). The two robot conditions and the two agent conditions did not differ.

\subsubsection{Disclosure}

People are more embarrassed in front of others, and feelings of social presence inhibit disclosure. We hypothesized participants would disclose less about themselves to the robots than to the computer agents. Participants did not answer consistently to questions about whether they were good listeners, had hurt someone in the past, treated obnoxious people well, or neglected to help someone in need, although there was a nonsignificant trend for those in the robot conditions to deny negative behavior, and women confessed more than men did.

We found significant differences, in the predicted direction, in how much participants talked about their own negative behavior. Word counts of disclosures (controlling for comprehension and gender, as noted earlier) indicated a significant overall effect of condition $(\mathrm{F}[3,81]=2.6, \mathrm{p}=.05)$ and a significant contrast. The participants in the agent conditions revealed more (28.6 words on average to the monitor agent; 22.6 to the projected agent) than those in the two robot conditions (16.3 words to the remote projected robot; 15.7 words to the collocated robot; contrast $\mathrm{F}=$ $4.8, \mathrm{p}<.05)$. Within the robot and the agent conditions, the differences were not significant.

\subsubsection{Influence}

There was a trend for the collocated robot to have more influence on participants' declaring they intended to exercise in the next 
week, read for pleasure, floss teeth, eat salads, and consumer less fatty food. The overall (multiple analysis of variance) MANOVA was not significant $(\mathrm{p}=.12)$ and a contrast of the collocated robot with the remote projected robot showed a tendency for intentions to be stronger in the collocated condition $(F=3.1, p=.08)$. There were no differences in the calories of candy bars eaten by participants.

\subsubsection{Conversational Memory}

We found no differences in participants' recognition of information from the robot from multiple-choice items. However, we found a difference in participants' open-ended answers to the item, "What did the robot say people do to keep their minds active?" The robot had told the participants "many people work on cross-word puzzles or do math in some way, like handling their finances. Some people play games like chess. Some people read for pleasure." We counted the number of these activities participants recalled, and found strong condition effects ( $F$ [3, $106]=3.8, \mathrm{p}=.01)$. The participants who interacted with the agents remembered most (2.5 items on average) as compared with the remote projected robot ( 2 items on average) and the collocated robot (1.4 items on average). Those in the agent conditions remembered significantly more than those in the robot conditions (contrast $\mathrm{F}=7.5, \mathrm{p}<.01$ ) and those in the remote projected robot condition remembered more than those in the collocated robot condition (contrast $\mathrm{F}=10.3, \mathrm{p}<.01$ ).

\subsubsection{Mental State, Experience, and Sense of \\ Presence}

After their conversation with the robot or agent, participants completed an online questionnaire. As noted earlier, the questions addressed participants' feelings during the conversation with the agent or robot. There were no differences in participants' reported mood or in their reports of mental effort.

On the other hand, in a multiple analysis of variance (MANOVA) examining the helpfulness of the agent or robot, the usefulness of the agent or robot's advice, and the participant's enjoyment of the conversation, those in the robot conditions felt the conversation significantly more helpful, useful, and enjoyable when they interacted with a robot versus an agent (monitor agent $=4.9$, projected agent $=4.8$; remote projected robot $=5.0$, collocated robot $=5.4 ; \mathrm{F}[3,108]=2.6, \mathrm{p}=.05)$. The agent vs. robots contrast was significant $(\mathrm{F}=4.0, \mathrm{p}<.05)$ and the remote robot vs. collocated robot contrast was significant as well $(\mathrm{F}=3.9, \mathrm{p}<.05)$. The agents were not significantly different.

Also, as expected, sense of presence differed across conditions. Those in the agent conditions felt less sense of presence (monitor agent $=4.2$, projected agent $=3.9$ ) than those in the remote robot $($ mean $=4.3)$ or those in the collocated robot condition $($ mean $=5$; $\mathrm{F}[3,108]=3.3, \mathrm{p}<.05)$. The agents were significantly different from the robots $(\mathrm{F}=4.3, \mathrm{p}<.05)$ and the collocated robot felt significantly more present than the remote projected robot $(\mathrm{F}=$ $5.3, \mathrm{p}<.05)$. The two agents were not significantly different.

\subsubsection{Attitudes}

There were consistent and significant condition differences in how participants rated the agents, remote robot, and collocated robot. Table 3 gives the descriptive statistics on the personality trait variables. Because of the number of traits measured, to minimize the chance of finding effects by chance, the hypotheses were tested using MANOVA. These analyses showed a significant effect overall $(\mathrm{F}[3,108]=5.6, \mathrm{p}<.01)$. The robots were rated more highly than the agents (contrast $\mathrm{F}=12.3, \mathrm{p}<.001$ ) and the collocated robot was rated more highly than the remote projected robot (contrast $F=5.1, p<.05$ ). As in other analyses, the two agents were not significantly different. Figure 5 summarizes these results; because they were not different, and for simplicity, we collapsed the two agent conditions in the figure.

Table 3. Means of Personality Trait Ratings of the Agents and Robots

\begin{tabular}{|l|c|c|c|c|}
\hline Trait & $\begin{array}{l}\text { Monitor } \\
\text { Agent }\end{array}$ & $\begin{array}{l}\text { Projected } \\
\text { Agent }\end{array}$ & $\begin{array}{l}\text { Remote } \\
\text { Projected } \\
\text { Robot }\end{array}$ & $\begin{array}{l}\text { Collocated } \\
\text { Robot }\end{array}$ \\
\hline Dominant & 4.37 & 4.35 & 4.57 & 4.59 \\
\hline Trustworthy & 3.64 & 3.89 & 4.04 & 4.33 \\
\hline Sociable & 3.87 & 3.69 & 3.94 & 4.17 \\
\hline Responsive & 4.12 & 4.08 & 4.37 & 4.91 \\
\hline Competent & 4.70 & 4.69 & 5.05 & 5.34 \\
\hline Respectful & 5.12 & 5.04 & 5.22 & 5.77 \\
\hline
\end{tabular}

Note. Standard error in both agent conditions is .23 and .16 in both robot conditions.

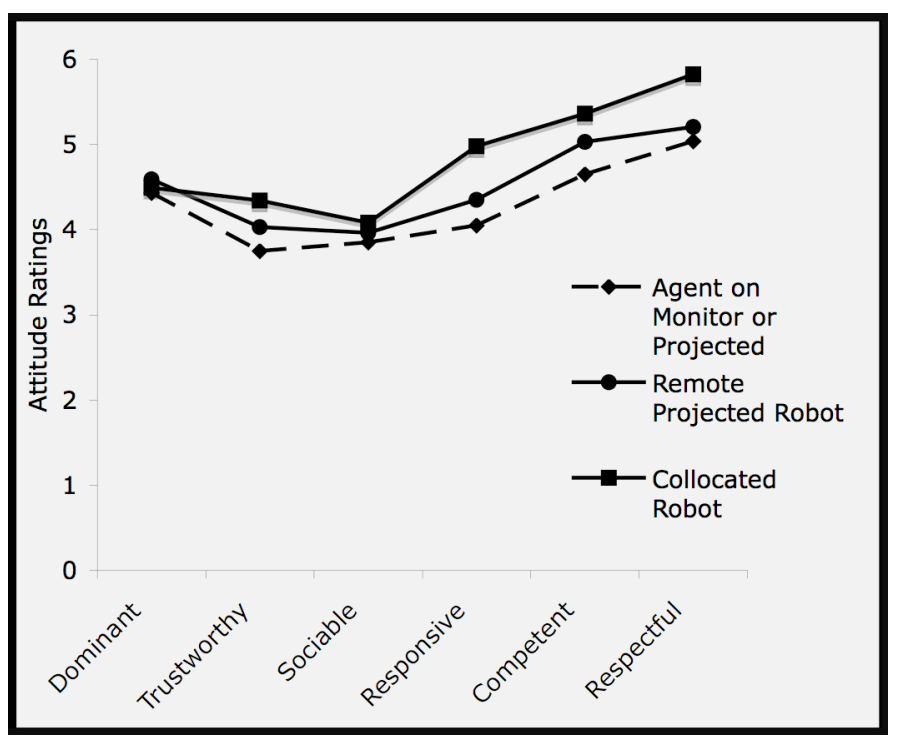

Figure 5. Rated personality traits of agents and robots.

We also asked the participants to rate the lifelikeness of the agent or robot with which they interacted (see Table 2). These ratings showed that participants perceived the robots to be significantly more lifelike than the agents (overall $\mathrm{F}=7.3, \mathrm{p}<.01$; contrast of agents with robots, $\mathrm{F}=10, \mathrm{p}<.001)$. For hypothesis tests, the two robots and the two agents were not significantly different from one another (but we noticed that the collocated robot was different from all the other conditions, $\mathrm{F}=9.8, \mathrm{p}<.001)$. The monitor agent was rated 2.8 , on average (on these four 7-point scales); the projected agent mean was 3 ; the projected remote 
robot mean was 3.4 , and the collocated robot mean was 3.9. We show these results in Figure 6.

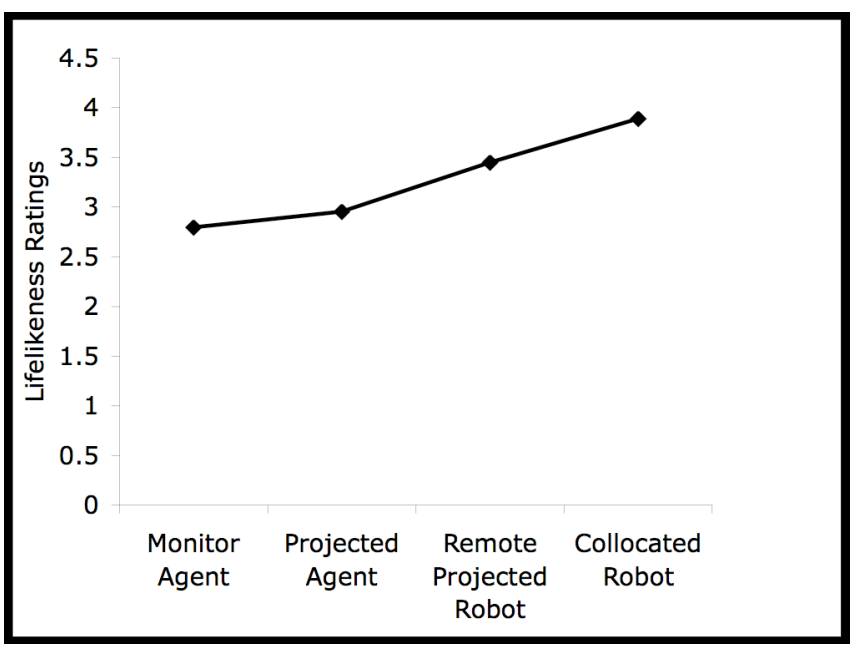

Figure 6. Average Lifelikeness Ratings of the Agents and Robots

\subsection{Summary of Results}

We tested three general hypotheses about the social impact of an agent versus a robot. Across all comparisons, we found modest support for Hypothesis 1, that a robot would have more social impact than a computer agent. In this study, the robots did not have more social influence on health behavior than the agents did, but the robots were more engaging (participants spent more time with the robots than with the agents). Participants also disclosed less to the robots than to the agents, indicating they had greater evaluation apprehension of the robots. Participants found the robots to be more helpful, to give better and more useful advice, and to be more effective communicators. They gave more positive personality trait ratings to the robot, and found the robots to be more lifelike.

In the behavioral data, we found little support for Hypothesis 2, that a collocated robot would have more social impact than a remote projected robot. Surprisingly, the remote robot had almost as much social influence as the collocated one. It was equally engaging, elicited equal disclosure, but may have had somewhat less influence. However, the participants did not rate the remote projected robot as highly when they evaluated its helpfulness and the usefulness of its advice, and effectiveness as a communicator. It was not rated as highly as the collocated robot on personality traits.

A somewhat surprising finding is that participants who interacted with an agent remembered more key pieces of information in a recall test than did those interacting with a robot, and those who interacted with the remote projected robot remembered more than those who interacted with the collocated robot. It would thus appear that participants who interacted with the collocated robot processed the information they received from the robot more shallowly. Perhaps they were simply distracted, as they were clearly more entertained in the collocated robot condition than in the remote projected robot condition or, even more so, in the agent conditions.

\section{DISCUSSION}

At the outset, this experiment examined only one instantiation of an agent and robot. We were constrained by our having only one robot to interact with participants, and the agent had to be modeled on the likeness of the robot in order to control for differences in appearance across conditions. In our previous research, we have shown that even seemingly small differences in the shape of the robot's head can affect participants' perceptions and attributions of the robot [13]. Had we chosen a different robot-agent pair to study, the results might be different. We speculate that a full bodied, immersive agent could be extremely engaging in some situations. We will not be able to claim generalizablity until others have replicated the study with other agent-robot comparisons. However, we note that our results are consistent with Yamato et al.'s comparison of an agent and robot rabbit [23]. Furthermore, even our rather primitive agent had some positive effects over the robot (e.g., on memory and disclosure). We believe our study has strong validity, for the comparisons we made, and begins to address the strategic question of using agents for research on robots.

\subsection{Implications for Research Strategies}

In this study, a robot had both advantages and disadvantages as compared with an agent. On the one hand, people liked the robot far better than the agent, on the other hand, they disclosed less and remembered fewer key pieces of information when interacting with the robot. These findings have implications both for the study of human-robot interaction and for choices of social technologies to implement for specific tasks.

With respect to methodology, our results show that embodied agents on a computer monitor cannot fully substitute for social robots in all studies of human-robot interaction. The agent and robot were not equivalent in their effects on people's behaviors or attitudes across all of our measures. At the same time, the results do suggest that a remote projected robot could be used to study many critical social processes, including engagement and disclosure. This finding opens up the possibility of sharing social robots among laboratories, given that adequate video and audio conferencing equipment were available.

Our findings suggest that choosing among a collocated robot, remote robot, and agent for specific purposes will require a consideration of the social and informational dimensions of the task at hand. For tasks that involve a lot of information transmission but relatively little social rapport (e.g., information kiosks), embodied agents should suffice. Likewise, for tasks that require users to reveal personal information, agents may be preferable. However, for tasks that are more relationship-oriented (e.g., a home companion), a collocated robot would seem to be best. Difficult choices will arise for tasks that involve a combination of information transmission, disclosure and relationship development, such as assistive robots. To make the best choice in such situations, we need to know more about the longer-term impact of interaction dynamics in humanrobot interaction.

The inability of robots to maximize information transmission, disclosure and social relationship development at the same time suggests a direction for future research: understanding how to design human-robot interaction to enhance understanding of the information provided by the robots. Robots that are sensitive to human behaviors and nonverbal communication may be an important first step in this direction [21]. Such robots might use a person's behavior to assess whether instructions were understood, or conversational strategies to elicit information that people are reluctant to disclose. 


\section{ACKNOWLEDGMENTS}

This research was supported by an ITR National Science Foundation grant IIS-0121426. We thank Hau-Yu Wong, Sean Gilroy, Greg Armstrong, Judy Matthews, and the People and Robots, Nursebot, and Social Robots project teams for their suggestions and help in this study.

\section{REFERENCES}

[1] Berry, D. C., Butler, L. T., de Rosis, F. Evaluating a realistic agent in an advice-giving task. International Journal of Human-Computer Studies, 65, 2005, 304-327.

[2] Bradner, E., \& Mark, G. Social presence with video and application sharing. In Proceedings of the ACM Conference on Supporting Group Work (GROUP'01). Sept 30-Oct 3, 2001, Boulder, CO). NY: ACM Press, 2001, 154-161.

[3] Guerin, B. Mere presence effects in humans. Journal of Experimental Social Psychology, 22, 1986, 38-77.

[4] Hall, M.A., Zheng, B., Dugan, E., Fabian, C., Kidd, K, Mishra, A., and Balkrishnan, R. Measuring patients' trust in their primary care providers. Medical Care Research and Review, 59 (3), Sept. 2002, 293-318.

[5] Hinds, P., D. Bailey. Out of sight, out of sync: Understanding conflict in distributed teams: An empirical investigation. Organization Science, 14(6), 2003, 615-532.

[6] Huang, W., Olson, J. S., \& Olson, G. M. (2002). Camera angle affects dominance in video-mediated communication. CHI 2002 Late Breaking Results (pp. 716-717).

[7] Jettmar, E. \& Nass, C. Adaptive testing: Effects on user performance. . In Proceedings of the Conference on Human Computer Systems CHI'02. (April 20-25, 2001, Minneapolis). NY: ACM Press, 2002, 129-134.

[8] Judge, T., \& Cable, D. M. The effect of physical height on workplace success and income: Preliminary test of a theoretical model. Journal of Applied Psychology, 89 (3), 2004, 428-441.

[9] Kiesler, S., \& Cummings, J. What do we know about proximity in work groups? A legacy of research on physical distance. In P. Hinds \& S. Kiesler, Distributed Work, Cambridge: MIT Press, 2002, 57-80.

[10] Lenzo, K.A., and Black, A.W., Theta, Cepstral, http://www.cepstral.com

[11] Levav, J., \& Fitzsimons, G. J. When questions change behavior: The role of ease of representation. Psychological Science, 17 (3), 2006, 207-213.

[12] Powers, A. An Easy To Use Dialogue Tool: AIMLE. Unpublished ms., HCII, Carnegie Mellon University, Pittsburgh, PA.
[13] Powers, A., \& Kiesler, S. The advisor robot: Tracing people's mental model from a robot's physical attributes. Conference on Human-Robot Interaction 2006. Salt Lake City, March 1-3, 2006, 218-225.

[14] Powers, A., Kramer, A. D. I., Lim, S., Kuo, J., Lee, S-L., Kiesler, S. Eliciting information from people with a gendered humanoid robot. Robot and Human Interactive Communication Proceedings. ROMAN 2005. The 14th IEEE International Workshop (Nashville, TE. Aug 14-15), 2005.

[15] Rakison, D. H. \& Poulin-Dubois, D. Developmental origin of the animate-inanimate distinction. Psychological Bulletin, 127 (2), 2001, 209-228 .

[16] Richman, W. L., Kiesler, S., Weisband, S., Drasgow, F. A meta-analytic study of social desirability distorion in computer-administered questionnaires, traditional questionnaires, and interviews. Journal of Applied Psychology, 84 (5), 1999, 754-775.

[17] Robinson, J. P., Shaver, P. R., \& Wrightsman, L. S. (Eds.), Measures of Personality and Social Psychological Attitudes. NY: Academic Press, 1991.

[18] Sheridan, T. B. Defining our terms. Presence, 1, 272-274.

[19] Simmons, R., et al., GRACE: An autonomous robot for the AAAI Robot Challenge, AAAI Magazine, 24, 2, 2003, 51-72.

[20] Tan, D. S., \& Czerwinski, M. Information voyeurism: Social impact of physical large displays on information privacy. In Proceedings of the Conference on Human Computer Systems CHI'03. (April 5-10, 2003, Ft. Lauderdale). NY: ACM Press, 2003, 748-749.

[21] Torrey, C. Powers, A., Marge, M., Fussell, S., \& Kiesler, S. Effects of adaptive robot dialogue on information exchange and social relation. Proceedings of the Conference on HumanRobot Interaction 2006. (Salt Lake City, March 1-3), 2006, 126-133.

[22] Welch, R. B. How can we determine if the sense of presence affects task performance? Presence, 8 (5), 1999, 574-577.

[23] Yamato, J., Shinozawa, K., Naya, F., Kogure, K. Evaluation of communication with robot and agent: Are robots better social actors than agents? In Proceedings of the 8th IFIP TC.13 International Conference on Human-Computer Interaction (INTERACT '01) (Tokyo, Japan, July 9-13), 2001, 690-691.

[24] Witmer, B. G., \& Singer, M. J. Measuring presence in virtual environments. (ARI Technical Report 1014). Alexandria, VA: U. S. Army Research Institute for the Behavioral and Social Sciences, 1998.

[25] Zajonc, R. B. Social facilitation. Science, 149, 1965, 269-274. 